\title{
Carbon dioxide insufflation is superior to air insufflation during endoscopic retrograde cholangiopancreatography: A randomized trial
}

\author{
Santosh Darisetty, Saravanan Arjunan ${ }^{1}$, Manu Tandan ${ }^{1}$, Rajesh Gupta ${ }^{1}$, \\ Mohan Ramchandani ${ }^{1}$, Duvvur Nageshwar Reddy ${ }^{1}$
}

Departments of Anesthesiology and ${ }^{1}$ Gastroenterology, Asian Institute of Gastroenterology, Hyderabad, Telangana, India

\begin{abstract}
Key words

Background: Carbon dioxide $\left(\mathrm{CO}_{2}\right)$ insufflation has been shown to be superior to air insufflation in colonoscopy, and double balloon enteroscopy. However, the value of $\mathrm{CO}_{2}$ insufflation in endoscopic retrograde cholangiopancreatography (ERCP) is not established. This study aims to assess the efficacy and safety of $\mathrm{CO}_{2}$ insufflation during ERCP. Materials and Methods: Consecutive patients referred for ERCP at a single center were randomized to either air or $\mathrm{CO}_{2}$ insufflation during ERCP. The primary objectives were a post-ERCP abdominal pain (measured by $10 \mathrm{~cm}$ visual analog scale [VAS] 30 and $90 \mathrm{~min}$, and $3 \mathrm{~h}$ and $24 \mathrm{~h}$ after ERCP). Secondary objectives included end-tidal $\mathrm{CO}_{2}\left(\mathrm{ETCO}_{2}\right)$ values and procedural complications. Results: We randomized 298 patients; 149 into air group and 149 into $\mathrm{CO}_{2}$ group. The VAS score for pain was higher in the air group compared to the $\mathrm{CO}_{2}$ group at $30 \mathrm{~min}$, with a median of 1 (interquartile range $1-0$ ) versus median of 1 (interquartile range $1-0$ ); $P=0.031$ and $90 \mathrm{~min}$ after the procedure with a median of 0 (interquartile range $1-0$ ) versus median of 0 (interquartile range $0-0$ ); $P=0.006$. There were no serious adverse events, and the $\mathrm{ETCO}_{2}$ was within normal limits in both groups. Conclusions: $\mathrm{CO}_{2}$ insufflation is superior to air insufflation during ERCP with regard to patient pain and discomfort and warrants wide adoption. Clinical Trials.gov registration number NCT 01321203.

Air insufflation, carbon dioxide insufflation, endoscopic retrograde cholangiopancreatogram
\end{abstract}

\section{Introduction}

To achieve adequate visualization of the gastrointestinal (GI) tract during endoscopy, adequate distension of the bowel is required. Conventionally, insufflation of air has been used. Insufflated air causes painful abdominal distension as it is not absorbed in the GI tract. There is also a possibility of combustion when used in combination with electrocautery. ${ }^{[1]}$

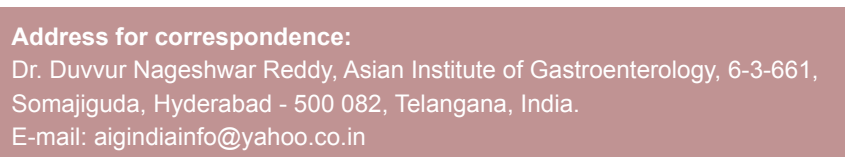

\begin{tabular}{|l|c|}
\hline \multicolumn{2}{|c|}{ Access this article online } \\
\hline \multirow{2}{*}{$\begin{array}{l}\text { Website: } \\
\text { www.jdeonline.in }\end{array}$} & Quick Response Code \\
\hline DOI: & \\
10.4103/0976-5042.180085 & \\
\hline
\end{tabular}

In 1986, Christopher Williams introduced the use of carbon dioxide $\left(\mathrm{CO}_{2}\right)$ in endoscopy to reduce the abdominal pain and discomfort, as it is rapidly absorbed. Currently, $\mathrm{CO}_{2}$ insufflation is widely used in colonoscopy, flexible sigmoidoscopy, and double balloon enteroscopy. ${ }^{[2-4]}$ However, $\mathrm{CO}_{2}$ insufflation has not been widely adopted in endoscopic retrograde cholangiopancreatography (ERCP).

There are three randomized controlled trials (RCTs) on $\mathrm{CO}_{2}$ insufflation in ERCP. These trials included limited number of patients and had conflicting data. ${ }^{[5-7]}$ Two concluded that

This is an open access article distributed under the terms of the Creative Commons Attribution-NonCommercial-ShareAlike 3.0 License, which allows others to remix, tweak, and build upon the work non-commercially, as long as the author is credited and the new creations are licensed under the identical terms.

For reprints contact: reprints@medknow.com

How to cite this article: Darisetty S, Arjunan S, Tandan M, Gupta R, Ramchandani M, Reddy DN. Carbon dioxide insufflation is superior to air insufflation during endoscopic retrograde cholangiopancreatography: A randomized trial. J Dig Endosc 2016;7:6-10. 
$\mathrm{CO}_{2}$ insufflation reduces postprocedural abdominal pain and distension. ${ }^{[5,6]}$ While the third trial concluded that the use of $\mathrm{CO}_{2}$ insufflation did neither increase nor decreased the postprocedural abdominal distension or pain. ${ }^{[7]}$ Therefore, we have compared $\mathrm{CO}_{2}$ insufflation to conventional air insufflation during ERCP with regard to abdominal pain, end-tidal $\mathrm{CO}_{2}\left(\mathrm{ETCO}_{2}\right)$ and complications.

\section{Materials and Methods}

All consecutive adult patients scheduled to undergo an ERCP at the Asian Institute of Gastroenterology in Hyderabad, India between August 2010 and November 2010, were recruited. The exclusion criteria were patients younger than 19 years, pregnancy, American Heart Association Class III-IV, a chronic obstructive pulmonary disease with known $\mathrm{CO}_{2}$ retention and those unable to give informed consent. The trial was reviewed by the Institutional review board and approved by the ethics committee. It has been registered with Clinical trial. gov, (NCT 01321203).

The subjects were randomized into air group (air insufflation) and $\mathrm{CO}_{2}$ group ( $\mathrm{CO}_{2}$ insufflation) by 1:1 variable block size using a computer-generated allocation sequence by a research assistant [Figure 1]. The allocation envelopes were opened just before the ERCP by the dedicated endoscopy assistant who was assigned to shuffle between air and $\mathrm{CO}_{2}$ insufflation. The endoscopist, anesthesiologist, and the recovery nurse were blinded to the type of insufflation used during the ERCP.

The variables monitored during ERCP were oxygen saturation, $\mathrm{ETCO}_{2}$, noninvasive blood pressure, electrocardiogram, and pulse rate. The patients were not intubated. We used a disposable nasal smart Capnoline $\mathrm{CO}_{2}$ sampling line to measure the $\mathrm{ETCO}_{2}$. The measurements were taken from

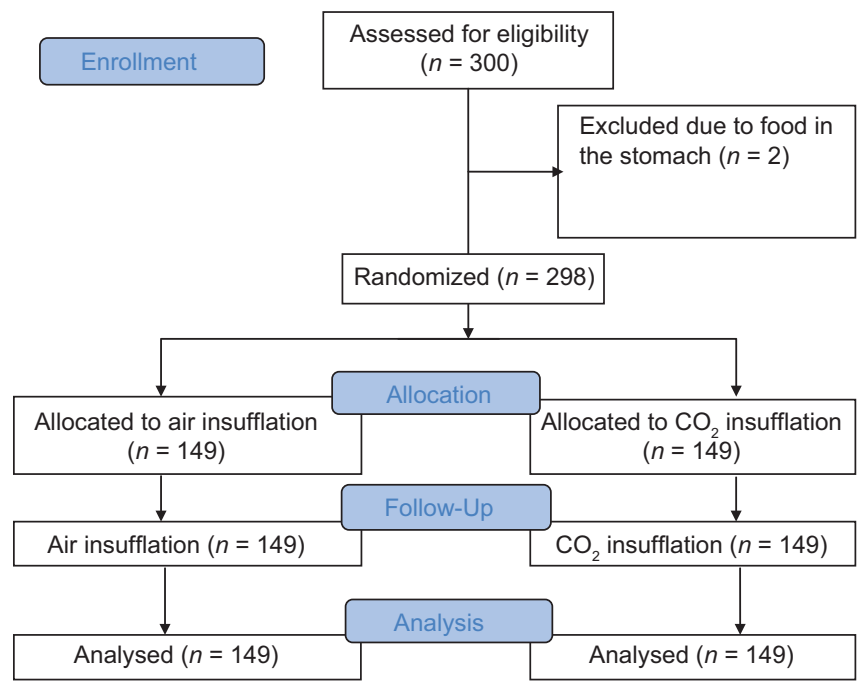

Figure 1: Flow chart showing enrollment and randomization of patients for both air and $\mathrm{CO}_{2}$ insufflation continuous monitoring of the $\mathrm{ETCO}_{2}$. Conscious sedation was administered by an anesthesiologist. The procedures were performed at the discretion of the consultant endoscopist. The endoscopists were instructed to aspirate out all the gastric fluid and air while intubating the patient and similarly aspirate out the gas at the end of ERCP before withdrawing the scope. The patients received either standard air or $\mathrm{CO}_{2}$ insufflations through the scope processor. The patients were moved to postanesthesia care unit (PACU) after the ERCP and were monitored by a dedicated nurse.

ERCP was done using an Olympus TJF Type 150 side viewing endoscope. Air insufflation was administered through the processor unit, and $\mathrm{CO}_{2}$ insufflation using the Olympus Endoscopic $\mathrm{CO}_{2}$ regulation unit (Gas Regulator, Crown, GF2-2503-JT6-F5; Yutaka Engineering, Tokyo, Japan) attached to the processor unit. The flow rate of $\mathrm{CO}_{2}$ has been designed to be similar to the flow rate of air. ${ }^{[5]}$ ERCP was performed under deep sedation. The bile duct and pancreatic duct cannulation were performed using a wire-guided cannulation with a papillotome or an ERCP catheter. ERCP was performed after a deep cannulation. All procedures were therapeutic in nature, such as lithotomy, papillotomy, or stenting. The patients were monitored by a dedicated nurse and were discharged from the PACU after they had become completely awake, and oriented with time, place, and person.

The primary objective was an evaluation of patient's postprocedure abdominal pain. A $0-10 \mathrm{~cm}$ visual analog scale (VAS) was used, with 0 representing "no pain" and 10 representing "very severe pain." The VAS pain score was recorded at $30 \mathrm{~min}, 90 \mathrm{~min}, 3 \mathrm{~h}$, and $24 \mathrm{~h}$ after the ERCP by a dedicated nurse blinded to the allocation of patients to insufflation groups.

\section{Statistical analysis}

This is a double-blinded randomized clinical study. A sample size of 149 per group having a power of $80 \%$ with a $5 \%$ level of significance was taken. The mean values were air group 0.65 and $\mathrm{CO}_{2}$ group 0.44 . There was a 0.21 difference between the means of the two groups in VAS score in the pilot study, with a combined standard deviation (SD) in the air and $\mathrm{CO}_{2}$ group of 0.727 . Statistical Analysis was performed using Statistical Packages for Social Sciences 13.0 version (SPSS Inc., Chicago, Illinois, USA). Comparisons of data between the air group and $\mathrm{CO}_{2}$ group were done using Wilcoxon rank sum test (VAS scores at 30, 90, $180 \mathrm{~min}$, and at $24 \mathrm{~h}$ ). Comparison between the two groups for categorical data was done using Chi-square test. Comparison between the two groups for continuous normal data was done using $t$-test.

\section{Results}

A total of three hundred patients were recruited and randomized between August 1, 2010, and November 7, 2010 (194 men and 
104 women; mean [SD] age 42.80 [14.45] years). Two patients were subsequently excluded due to the presence of residual food in the stomach. Enrollment and randomization of the patients are shown in Figure 1.

This study was conducted to see the efficacy and safety of $\mathrm{CO}_{2}$ usage for ERCP and whether it would reduce the postprocedure pain caused by bowel distension with the insufflation of gas. The primary outcome of the study was median abdominal pain score (VAS score). It was significantly higher in air group than $\mathrm{CO}_{2}$ group at 30 and 90 min [Table 1]. Figure 2 shows the significant difference between the two groups in the VAS score for abdominal pain at $30 \mathrm{~min}$ and $90 \mathrm{~min}$ postprocedure. The median VAS scores at $180 \mathrm{~min}$ and $24 \mathrm{~h}$ did not show any statistically significant differences with $P<0.181$ and 0.321 , respectively. The other variables considered were the indications for ERCP, endoscopists' experience, procedure time, and post-ERCP pancreatitis [Table 2]. They were not of much significance.

The secondary endpoint was the safety of $\mathrm{CO}_{2}$ insufflation. The normal $\mathrm{ETCO}_{2}$ volume ranges from 30 to $37 \mathrm{mmHg}$. In this study population, the average $\mathrm{ETCO}_{2}$ in $\mathrm{CO}_{2}$ group was $32.30 \pm 17.18$ and air group was $26.32 \pm 9.06 \mathrm{mmHg}$. None of the patients in this study population had any adverse event secondary to hypercarbia.

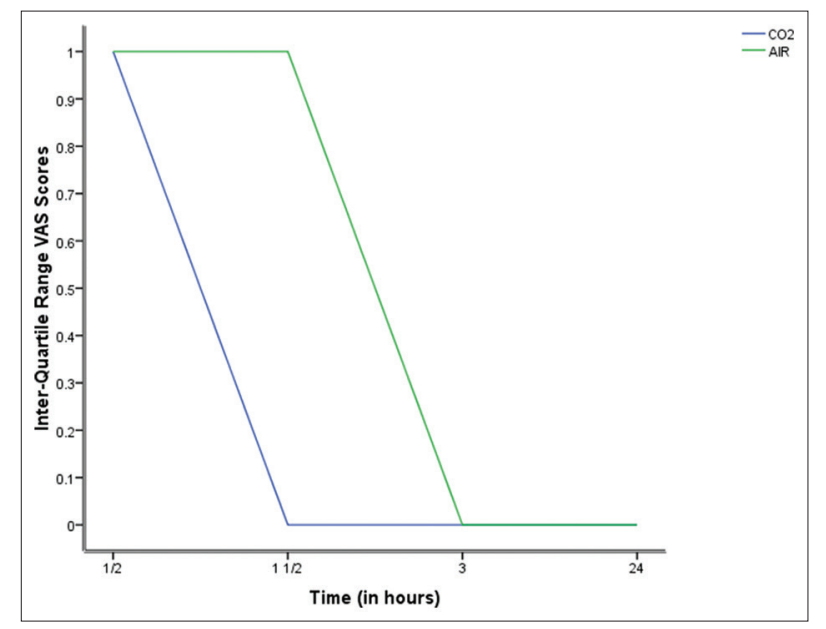

Figure 2: Line diagram for visual analogue scale score for two groups
There was no difference in the groups in the time taken for the ERCP procedures. Similarly, there were no differences between the two groups in the mean requirement of propofol for sedation or the mean dose of intravenous buscopan used to control peristalsis.

\section{Discussion}

This clinical trial revealed that insufflation with $\mathrm{CO}_{2}$ during ERCP reduced postprocedure abdominal distension and pain in comparison to air insufflation. It also demonstrated that $\mathrm{CO}_{2}$ can be safely used for insufflation during ERCP.

The insufflated air or $\mathrm{CO}_{2}$ during ERCP leads to postprocedure abdominal discomfort. Since ambient air is not well absorbed, it must either be suctioned at the end of the procedure or passed from the GI tract as flatus. The residual air can cause bowel distention and abdominal pain. $\mathrm{CO}_{2}$ has the advantage of being rapidly absorbed from the GI lumen into the blood stream and eliminated through respiration. ${ }^{[1]}$

There were only three randomized clinical trials on insufflation of $\mathrm{CO}_{2}$ during ERCP. The first trial was published in Endoscopy in 2007; wherein the author randomized 118 patients to air and $\mathrm{CO}_{2}$ insufflation for ERCP. ${ }^{[5]}$ Similarly, in the second trial published in GIE 2009, the author randomized 100 subjects. ${ }^{[6]}$ In both the studies, the subjects had significantly lesser pain and abdominal distention in the $\mathrm{CO}_{2}$ insufflation group compared to the air insufflation group. However, in the more recent study published in GIE 2010, the author randomized 157 patients undergoing ERCP to $\mathrm{CO}_{2}$ insufflation or air insufflation. Abdominal pain was assessed using VAS and abdominal girth measurement. $\mathrm{PCO}_{2}$ was measured with percutaneous capnography. ${ }^{[7]}$ The outcome of this trial was contradictory to the first 2 studies as there was no significant difference in the abdominal distension and pain though it showed that $\mathrm{CO}_{2}$ is safe for insufflation during ERCP. All the three studies mentioned above had the same primary objective as this study. The primary outcome of our study was similar to the initial two trials and contradictory to the recent trial.

In a more recent study which compared $\mathrm{CO}_{2}$ and air insufflation during ERCP, the main concern was that VAS score

\begin{tabular}{|c|c|c|c|c|c|c|c|}
\hline Time (in h) & Groups & Number & $\begin{array}{l}\text { Minimum } \\
\text { score }\end{array}$ & $\begin{array}{l}\text { Maximum } \\
\text { score }\end{array}$ & $\begin{array}{c}\text { Median } \\
\text { score }\end{array}$ & $\begin{array}{c}\text { Interquartile range } \\
\text { (Q3-Q1) score }\end{array}$ & $P$ \\
\hline \multirow[t]{2}{*}{$1 / 2$} & Air & 149 & 0 & 8 & 1 & $1-0$ & 0.031 \\
\hline & $\mathrm{CO}_{2}$ & 149 & 0 & 3 & 1 & $1-0$ & \\
\hline \multirow[t]{2}{*}{$1 \frac{1}{2}$} & Air & 149 & 0 & 4 & 0 & $1-0$ & 0.006 \\
\hline & $\mathrm{CO}_{2}$ & 149 & 0 & 2 & 0 & $0-0$ & \\
\hline \multirow[t]{2}{*}{3} & Air & 149 & 0 & 2 & 0 & $0-0$ & 0.181 \\
\hline & $\mathrm{CO}_{2}$ & 149 & 0 & 2 & 0 & $0-0$ & \\
\hline \multirow[t]{2}{*}{24} & Air & 149 & 0 & 2 & 0 & $0-0$ & 0.321 \\
\hline & $\mathrm{CO}_{2}$ & 149 & 0 & 2 & 0 & $0-0$ & \\
\hline
\end{tabular}




\begin{tabular}{|c|c|c|}
\hline & $\mathrm{CO}_{2}$ group & Air group \\
\hline Indications for ERCP & $\begin{array}{l}\text { Biliary or pancreatic } \\
\text { pathology }\end{array}$ & $\begin{array}{l}\text { Biliary or pancreatic } \\
\text { pathology }\end{array}$ \\
\hline Endoscopists' experience & $\begin{array}{l}\text { More than } 500 \\
\text { therapeutic ERCPs }\end{array}$ & $\begin{array}{l}\text { More than } 500 \\
\text { therapeutic ERCPs }\end{array}$ \\
\hline Procedure time & 17 min (median) & $18 \min$ (median) \\
\hline Post-ERCP pancreatitis & 3 patients & 4 patients \\
\hline
\end{tabular}

$\mathrm{ERCP}=$ Endoscopic retrograde cholangiopancreatography, $\mathrm{CO}_{2}=$ Carbon dioxide

at $1 \mathrm{~h}$ could have been influenced by the effect of sedation..$^{[7]} \mathrm{To}$ address this issue, we conducted this clinical trial and looked at the VAS at $30 \mathrm{~min}, 90 \mathrm{~min}, 3 \mathrm{~h}$, and $24 \mathrm{~h}$.

Post-ERCP patients were reviewed by the anesthesiologist and discharged from the PACU after the patients were completely awake, orientated to time, place, and person. Patients' abdominal pain was assessed with VAS scale. We felt that the assessment of pain during ERCP was important to evaluate the impact of $\mathrm{CO}_{2}$ insufflation compared to conventional air insufflation. However, this was not possible as all our patients were sedated during the procedure. Thus, we took 30 min postprocedure as the closest time frame since most of the patients would have recovered from the influence of sedation. VAS score at $30 \mathrm{~min}$ was significant, as the lesser abdominal pain was recorded in $\mathrm{CO}_{2}$ group compared to air group. The VAS score at 90 min showed significantly lesser abdominal pain in $\mathrm{CO}_{2}$ insufflation group compared to the air insufflation group. This can be taken as a surrogate marker for the discomfort experienced during the procedure.

VAS scores to assess postprocedure pain at $3 \mathrm{~h}$ and $24 \mathrm{~h}$ did not show any significant difference. This was probably because of a reduction in postprocedure residual air or $\mathrm{CO}_{2}$ by the passage of flatus or by its absorption along the GI lumen. The patients who had pain that lasted beyond $3 \mathrm{~h}$ were due to causes which were not directly related to insufflation. ERCP is a high-risk procedure and carries complications that need to be recognized early for immediate remedy or intervention. Pain is often the first sign of complication. Therefore, the intensity and duration of pain post-ERCP with the usage of air insufflation can be reduced with the usage of $\mathrm{CO}_{2}$ for insufflation. ${ }^{[8,9]}$

The presence of residual $\mathrm{CO}_{2}$ or air in the small bowel and colon during and after the procedure leads to increase in intra-intestinal pressure. Raised intra-intestinal pressure with marked residual gas is assumed to increase the risk of development of pancreatitis. ${ }^{[10]}$ In view of these points, we should consider the use of $\mathrm{CO}_{2}$ insufflation as it is absorbed rapidly when compared to air during ERCP.

We monitored $\mathrm{ETCO}_{2}$ which is a noninvasive technique of $\mathrm{CO}_{2}$ monitoring during ERCP. ETCO ${ }_{2}$ is a valid surrogate marker for $\mathrm{PaCO}_{2}$ which is invasive and requires a blood sample. There was a mild increase of $\mathrm{ETCO}_{2}$ in $\mathrm{CO}_{2}$ group but was within normal range. This was probably because Jaurnal of Digestive Endoscopy Vol 7 | Issue 1 | January-March 2016 the $\mathrm{CO}_{2}$ for insufflation was eventually absorbed through colonic mucosa into the splanchnic circulation and excreted from the lung. We used conscious sedation with Propofol during ERCP. ${ }^{[11]}$ All the subjects were monitored closely and no incidence of hypoxia, hypercapnea, or hypotension was reported. The incidence of procedure-related complications such as cholangitis and pancreatitis were similar in both groups.

The equipment required for $\mathrm{CO}_{2}$ insufflation is Olympus Endoscopic $\mathrm{CO}_{2}$ regulation unit which is connected to the processor (Gas Regulator, Crown, GF2-2503-JT6-F5; Yutaka Engineering, Tokyo, Japan). It is a onetime investment. $\mathrm{CO}_{2}$ is an inexpensive gas, so is cost-effective to use it for insufflation in all endoscopic procedures.

The limitation of the study was that it was a single center trial. $\mathrm{CO}_{2}$ insufflation during ERCP has been proven to be better than air as shown in multiple RCTs done with other endoscopic procedures. Some stated that air insufflation may be regarded as medical malpractice and that there is no reason to continue using air for insufflation in the future. ${ }^{[1]}$

\section{Conclusion}

This double-blinded RCT revealed that insufflation with $\mathrm{CO}_{2}$ during ERCP reduces abdominal distension and postprocedure pain in comparison to air insufflation. Based on our results, we recommend that $\mathrm{CO}_{2}$ can be safely used in ERCP practice. It has been registered with Clinical trial.gov, and the registration number is NCT 01321203.

\section{Acknowledgment}

I would like to mention a special word of thanks to Yanadi Reddy our Biostatistician for helping us out with the statistics.

\section{Financial support and sponsorship \\ Nil.}

\section{Conflicts of interest}

There are no conflicts of interest.

\section{References}

1. Bretthauer M. Turning science into clinical practice - The case of carbon dioxide insufflation. Endoscopy 2010;42:1104-5.

2. Bretthauer M, Lynge AB, Thiis-Evensen E, Hoff G, Fausa O, Aabakken L. Carbon dioxide insufflation in colonoscopy: Safe and effective in sedated patients. Endoscopy 2005;37:706-9.

3. Bretthauer M, Hoff G, Thiis-Evensen E, Grotmol T, Holmsen ST, Moritz V, et al. Carbon dioxide insufflation reduces discomfort due to flexible sigmoidoscopy in colorectal cancer screening. Scand J Gastroenterol 2002;37:1103-7.

4. Domagk D, Bretthauer M, Lenz P, Aabakken L, Ullerich H, Maaser C, et al. Carbon dioxide insufflation improves intubation depth in double-balloon enteroscopy: A randomized, controlled, double-blind trial. Endoscopy 2007;39:1064-7.

5. Bretthauer M, Seip B, Aasen S, Kordal M, Hoff G, Aabakken L. Carbon 
dioxide insufflation for more comfortable endoscopic retrograde cholangiopancreatography: A randomized, controlled, double-blind trial. Endoscopy 2007;39:58-64.

6. Maple JT, Keswani RN, Hovis RM, Saddedin EZ, Jonnalagadda S, Azar RR, et al. Carbon dioxide insufflation during ERCP for reduction of postprocedure pain: A randomized, double-blind, controlled trial. Gastrointest Endosc 2009;70:278-83.

7. Dellon ES, Velayudham A, Clarke BW, Isaacs KL, Gangarosa LM, Galanko JA, et al. A randomized, controlled, double-blind trial of air insufflation versus carbon dioxide insufflation during ERCP. Gastrointest Endosc 2010;72:68-77.

8. Stevenson GW, Wilson JA, Wilkinson J, Norman G, Goodacre RL. Pain following colonoscopy: Elimination with carbon dioxide. Gastrointest Endosc 1992;38:564-7.
9. Bretthauer M, Thiis-Evensen E, Huppertz-Hauss G, Gisselsson L, Grotmol T, Skovlund E, et al. NORCCAP (Norwegian colorectal cancer prevention): A randomised trial to assess the safety and efficacy of carbon dioxide versus air insufflation in colonoscopy. Gut 2002;50:604-7.

10. Groenen MJ, Moreels TG, Orlent H, Haringsma J, Kuipers EJ. Acute pancreatitis after double-balloon enteroscopy: An old pathogenetic theory revisited as a result of using a new endoscopic tool. Endoscopy 2006;38:82-5.

11. Ong WC, Santosh D, Lakhtakia S, Reddy DN. A randomized controlled trial on use of propofol alone versus propofol with midazolam, ketamine, and pentazocine "sedato-analgesic cocktail" for sedation during ERCP. Endoscopy 2007;39:807-12

\section{"Quick Response Code" link for full text articles}

The journal issue has a unique new feature for reaching to the journal's website without typing a single letter. Each article on its first page has a "Quick Response Code". Using any mobile or other hand-held device with camera and GPRS/other internet source, one can reach to the full text of that particular article on the journal's website. Start a QR-code reading software (see list of free applications from http://tinyurl.com/ yzlh2tc) and point the camera to the QR-code printed in the journal. It will automatically take you to the HTML full text of that article. One can also use a desktop or laptop with web camera for similar functionality. See http://tinyurl.com/2bw7fn3 or http://tinyurl.com/3ysr3me for the free applications. 